This item was submitted to Loughborough's Research Repository by the author.

Items in Figshare are protected by copyright, with all rights reserved, unless otherwise indicated.

\title{
Numerical simulation of a GDI engine flow using LES and POD
}

PLEASE CITE THE PUBLISHED VERSION

http://dx.doi.org/10.4271/2016-01-0598

\section{PUBLISHER}

(C) SAE International

\section{VERSION}

NA (Not Applicable or Unknown)

\section{PUBLISHER STATEMENT}

This work is made available according to the conditions of the Creative Commons Attribution-NonCommercialNoDerivatives 4.0 International (CC BY-NC-ND 4.0) licence. Full details of this licence are available at: https://creativecommons.org/licenses/by-nc-nd/4.0/

\section{LICENCE}

CC BY-NC-ND 4.0

\section{REPOSITORY RECORD}

Beavis, Nicholas J., Salah S. Ibrahim, and W. Malalasekera. 2016. "Numerical Simulation of a GDI Engine Flow Using LES and POD”. figshare. https://hdl.handle.net/2134/21155. 


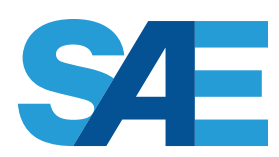

\section{Numerical Simulations of a GDI Engine Flow Using LES and POD}

\section{Nicholas J. Beavis, Salah S. Ibrahim, and Weeratunge Malalasekera}

Loughborough University

CITATION: Beavis, N., Ibrahim, S., and Malalasekera, W., "Numerical Simulations of a GDI Engine Flow Using LES and POD," SAE Technical Paper 2016-01-0598, 2016, doi:10.4271/2016-01-0598.

Copyright (C) 2016 SAE International

\begin{abstract}
This paper presents the findings from a numerical study of a gasoline direct injection engine flow using the Large Eddy Simulation (LES) modelling technique. The study is carried out over 30 successive engine cycles.
\end{abstract}

The study illustrates how the more simple but robust Smagorinsky LES sub-grid scale turbulence model can be applied to a complex engine geometry with realistic engineering mesh size and computational expense whilst still meeting the filter width requirements to resolve the majority of large scale turbulent structures.

Detailed description is provided here for the computational setup, including the initialisation strategy. The mesh is evaluated using a turbulence resolution parameter and shows the solution to generally resolve upwards of $80 \%$ of the turbulence kinetic energy. The calculated mean and fluctuating velocity components have been validated across multiple cutting planes at key crank angles within the intake stroke with good agreement obtained against experimental data and compared with RANS model predictions.

A Proper Orthogonal Decomposition (POD) technique is then used to evaluate the in-cylinder flow field with the results focusing around the eigenvalue/energy content and time coefficients associated with each mode. The findings have shown how this technique can be used to assess the amount of small scale turbulence generated at the point of spark timing, the level of flow field cyclic variability and the degree of statistical convergence to be expected from an ensemble average result based on the number of cycles and the level of cyclic variability present in the flow field.

\section{Introduction}

The benefits of gasoline direct injection (GDI) over a port-fuel injection strategy are well known: better fuel metering for improved indicated specific efficiency, reduced unburned hydrocarbons during cold start and transient excursions, reduced knock propensity, eliminated fuel transient delay from port to cylinder, and the ability to operate across multiple injection strategies. In spite of these benefits, the GDI engine still holds a number of research challenges. Cycletocycle variability $(\mathrm{CCV})$ in SI engines has long been a subject of interest; a literature survey by [1] suggested that up to a $10 \%$ improvement in fuel consumption would be achievable if it was possible to eliminate $\mathrm{CCV}$ entirely. It is not just the direct impact that $\mathrm{CCV}$ has on engine efficiency, there is also a significant indirect impact whereby manufacturers have to sub-optimally design engines to ensure they meet important design requirements including: retarded timing and reduced compression ratio to avoid abnormal combustion phenomenon, lower than limit emissions output or additional after-treatment to ensure the engine is always legislation compliant and less aggressive combustion strategies to meet consumer drivability needs.

The internal combustion engine (ICE) is a hostile and difficult to access environment and although significant effort has been applied into the research and development of experimental methods, the use of computational techniques (validated by experimental data) remains an integral part of research and development activities. Traditionally a Reynolds Averaged Navier-Stokes (RANS) approach to turbulence modelling has been used in ICE 3D-CFD modelling $[\underline{2}, \underline{3}]$ due to fairy high Reynolds numbers, immaturity of Sub-Grid Scale (SGS) closure models and insufficient computing power, but this approach has inherent limitations. The time or Favre weighted averaging techniques cause information related to the fluctuating component of the flow field to be lost, making investigations into unsteady phenomenon like CCV difficult at best. Within the LES context, the large scale eddies are solved directly on a cycle-by-cycle basis, with only the small scale eddies modelled by a SGS model. The use of LES within industry is emergent and input from academia is key for providing methods by which these new tools can be used for improved understanding, and ultimately, improved engine design.

In this study, the authors have investigated how a fairly modest grid size and computing resources can be combined with a relatively simple but more robust SGS modelling approach, and applied to a complex engine geometry realistic of a typical commercial engine design. The paper builds on the work of $[\underline{4}, \underline{5}]$ by utilising a POD methodology to 
investigate $\mathrm{CCV}$ within the in-cylinder flow field and highlights opportunities for applying this approach in an industrial context for quantitatively comparing engine designs with regard to $\mathrm{CCV}$.

This paper will first provide an outline of the turbulence and POD methodologies used. Next follows a description of the numerical model including boundary and initial conditions and computational setup. The results and discussion section provides evidence to show mesh (and hence SGS filter width) suitability, validation against available experimental data and the application of POD for evaluating $\mathrm{CCV}$. The final section will provide a summary of the conclusions found during this study.

\section{Turbulence Modelling}

As mentioned above, this study applies an LES approach whereby the large scale flow motions are solved directly via the Navier-Stokes ( $\mathrm{N}$ S) equations and only the small scale motions defined by the cell size or filter width are modelled at a SGS level.

In a turbulent flow, the flow field is typically decomposed via the Reynolds Decomposition into a mean component $\bar{u}_{i}$ and a fluctuating component $u_{i}^{\prime}$ (or in an LES context, the filtered and SGS components respectively), here shown for velocity and defined by equation (1).

$$
u_{i}=\bar{u}_{\imath}+u_{i}^{\prime}
$$

When this decomposition is introduced into the N-S equations, it drives the need for modelling of the SGS stresses and more specifically, the turbulence viscosity term. This study uses a turbulence viscosity closured approach as proposed by Smagorinsky [6] , based on a local equilibrium assumption such that production and dissipation of SGS turbulence kinetic energy are assumed to be equal. The SGS turbulence viscosity $\left(v_{\mathrm{T}}\right)$ is modelled as shown in equation (2) below and closes the N-S equations.

$$
v_{T}=\left(C_{S} \Delta\right)^{2}|\bar{S}|
$$

Where $C_{S}$ is the Smagorinsky constant, $\Delta$ is the filter width and $\bar{S}$ is the Favre filtered strain rate tensor. The limitations of this SGS modelling approach are well known (overly dissipative, simplified SGS kinetic energy model, no dynamic adjustment of $C_{s}$ ), but it has been proven to be more robust than more complex SGS models that include test filtering or additional transport equations, and to provide good results when applied with an appropriate grid size that reduces the dependence of the final solution on the SGS model. It is this increased robustness and simplicity that are the drivers for its use in this study.

\section{The Proper Orthogonal Decomposition Methodology}

The Proper Orthogonal Decomposition (POD) methodology was first applied to turbulent flows by [7] but the 'method of snapshots' was introduced later by [ $[\underline{]}]$ and was found to be less computationally expensive than other POD methods when applied in the context of ICE's, hence is the focus of this study. A brief summary of the 'method of snapshots' is presented here.

POD is the decomposition of a time dependent velocity field $u(x, t)$ (or scalar distribution) into a linear combination of $M$ spatial basis functions; POD modes denoted by $\psi^{(k)}(x)$ and time-dependent coefficients $a^{(k)}(t)$, as defined in equation (3)

$$
u(x, t)=\sum_{k=1}^{M}\left(a^{(k)}(t) \cdot \psi^{(k)}(\boldsymbol{x})\right)
$$

Where $\mathrm{k}=1,2, \ldots, \mathrm{M}$.

Using the 'method of snapshots', where $M$ is the instantaneous velocity field or snapshot (and equates to an engine cycle in this case) and $N$ is the position within the domain, a matrix $c$ can be formed as defined by equation (4)

$$
c_{m}^{n}=\left[\begin{array}{ccc}
c_{1}^{1} & \ldots & c_{1}^{N} \\
\vdots & \ddots & \vdots \\
c_{M}^{1} & \ldots & c_{M}^{N}
\end{array}\right]
$$

A $M \mathrm{x} M$ the covariance matrix $C$ is formed via $\mathrm{C}=\mathrm{CC}^{\mathrm{T}}$. Thus the following eigenvalue equation can be solved:

$$
C \cdot A^{(k)}=\lambda^{(k)} \cdot A^{(k)}
$$

Equation (5) is then solved for the $M$ eigenvalues $\lambda^{(k)}$ and $M$ eigenvectors $A^{(k)}$ and typically ordered in descending order to indicate the modes containing the largest fraction of the total flow field energy, where the energy content present in a particular mode is defined as the square of the modal eigenvalue.

Finally, $M$ POD modes $\psi^{(k)}(x)$ are formed via equation (6), where each mode has the same structure as each of the snapshots of the original velocity field.

$$
\psi_{d}^{(k)}\left(x_{n}\right)=\sum_{k=1}^{M}\left(A_{m}^{(k)} \cdot \boldsymbol{u}_{d}^{(k)}\left(x_{n}\right)\right)
$$

The eigenvalues (or kinetic energy) associated with each mode gives an indication of the structural complexity of the flow. When the modes are ordered by quantity of energy contained:

- A rapid decrease in eigenvalue magnitude where the majority of flow energy is contained within the first few modes characterises a flow field with large scale dominant flow structures

- A gradual decrease in eigenvalue magnitude where the majority of the flow energy is spread across many modes characterises a flow field with many weak and smaller scale flow structures.

Note that due to the temporal variation in computational domain size through an engine cycle, a 'phase-dependent' POD analysis has been applied in this study, where a new POD analysis is performed for 
each crank angle of interest. 'Phase-independent' POD analyses have been completed [9] but are not the subject of this study.

\section{The Numerical Model and Physical Sub-Models}

The numerical model was developed using CFD code STAR-CD (ver 4.20) and is a detailed representation of the experimental setup used to validate the CFD results. The experimental engine is a single cylinder optical research engine based on the combustion chamber of a V8 engine with pent-roof cylinder head, pancake piston crown, four valves per cylinder and has negligible to slightly negative valve overlap at the condition used in this study. The engine geometry and experimental setup used to obtain the High Speed Digital Particle Image Velocimetry (HSDPIV) data is described in detail in $[\underline{10}, \underline{11}]$, thus will not be described further in this paper.

\section{The Computational Domain}

The computational domain is shown in Figure 1. The domain was extended both upstream and downstream to allow sufficient time for turbulence to develop prior to the cylinder and to prevent recirculating flow around the flow outlet, respectively. The mesh was specifically developed to ensure high levels of cell uniformity and quality. The final mesh contained approximately 2.2 million cells at Bottom Dead Centre (BDC) and had a typical cell size within the cylinder of approximately $0.8 \mathrm{~mm}^{3}$.

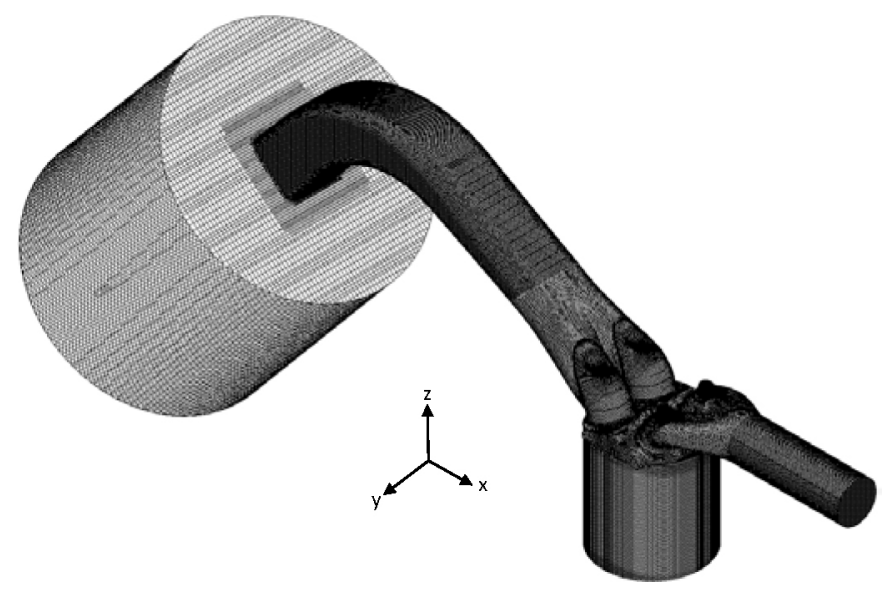

Figure 1. Computational mesh

\section{Boundary and Initial Conditions}

The inflow at the intake plenum and outflow at the exhaust port outlet were specified as a constant-pressure and constant-temperature environments in the absence of time varying experimental data. RANS predictions confirmed that the domain was extended sufficiently far upstream and downstream such that a steady pressure boundary was adequate to correctly predict the intake and exhaust system wave dynamics [12]. A turbulence intensity of $10 \%(0.1)$ was imposed at both the inflow and outflow and the turbulence length scale as $10 \%$ of the hydraulic diameter. An unsteady turbulence perturbation at the inflow was not implemented in this particular study since it was considered that the inflow was sufficiently upstream of the cylinder for correct turbulence levels to form prior to the intake valves. The numerical boundary conditions are summarised in Table 1.
Table 1. Numerical boundary conditions

\begin{tabular}{|l|l|}
\hline Engine Speed & $1500(\mathrm{rpm})$ \\
\hline Inflow Pressure & $0.453(\mathrm{bar})$ \\
\hline Inflow Temperature & $301(\mathrm{~K})$ \\
\hline Inflow Turbulence & $\begin{array}{l}\text { Intensity: 0.1 (none) } \\
\text { Length scale: } 0.0048(\mathrm{~m})\end{array}$ \\
\hline Outflow Pressure & 1.023 (bar) \\
\hline Outflow Temperature & $784(\mathrm{~K})$ \\
\hline Outflow Turbulence & Intensity: 0.1 (none) \\
\hline Wall Temperatures & Length scale: $0.001(\mathrm{~m})$ \\
\hline
\end{tabular}

The model was initialised by first running a RANS cycle, then an LES initialisation cycle was run (of which the results were discarded), then the simulation continued for a further 29 cycles. As expected, analysis of cylinder pressure curve data for all cycles showed that the first LES cycle was indeed abnormally high compared to all other LES cycles and thus confirm the approach to neglect the first initialisation cycle.

\section{Computational Setup}

The MARS (Monotone Advection and Reconstruction Scheme) second-order accurate differencing scheme was used for turbulence kinetic energy, turbulence dissipation, momentum and energy equations. The PISO (Pressure Implicit with Splitting of Operator) pressure-correction algorithm $[\underline{13}, \underline{14}]$ was used to provide approximately second-order time accuracy, with a moderate amount of pressure under-relaxation to further improve solver stability.

The time-step was set at $5.6 \times 10^{-6} \mathrm{~s}$ (equating to approximately $0.05 \mathrm{ca} /$ time-step) except around valve opening and closing periods where it was set to $1.1 \times 10^{-6} \mathrm{~s}$ (approximately $0.01 \mathrm{ca} /$ time-step). This provided adequate solution stability, an average Courant-Friedrichs- Lewy (CFL) number of less than one and a solver time of approximately 3 days per complete engine cycle.

The Smagorinsky constant $\left(C_{s}\right)$ was set to $0.02[\underline{15}]$ and the filter width $(\Delta)$ was defined by equation (7), where $V$ is the cell volume.

$$
\Delta=\sqrt[3]{V}
$$

\section{Results and Discussion}

\section{Mesh Suitability}

Since the solution is dependent on the filter width, the mesh suitability to capture the length scales present within the flow field, and hence a sufficient quantity of the flow turbulence kinetic energy, is not known a priori with a non-solution adaptive gridding approach. 
The turbulence resolution parameter originally proposed by Pope [16] has been used in this study to assess the suitability of the mesh, and is defined by equation (8):

$$
M_{\text {res }}(x, t)=\frac{k_{r e s}(x, t)}{k_{r e s}(x, t)+k_{s g s}(x, t)}
$$

Thus as $M_{\text {res }}(x, t)$ approaches zero the solution approaches that of RANS, and as $M_{r e s}(x, t)$ approaches one the solution approaches that of DNS. Values of $M_{\text {res }}(x, t)>80 \%$ are considered as a requirement to be deemed a 'Large' eddy simulation [17], whereas values between $60 \%-80 \%$ are considered a 'Very Large' eddy simulation.

In this study the turbulence resolution parameter has been evaluated at three different crank angles through the intake and compression strokes, along three swirl cutting planes (z-axis) with the results being shown in Figure 2, Figure 3 and Figure 4.

The results show that generally turbulence resolution $(M(x, t))$ is greater than $80 \%$ with a small degree of deviation down to approximately $60 \%$ resolution at earlier crank angles due to insufficient resolution of the high shear regions around the intake valve jet. In the interests of maintaining a computational expense that is compatible within an engineering workflow, no further mesh refinement was completed.

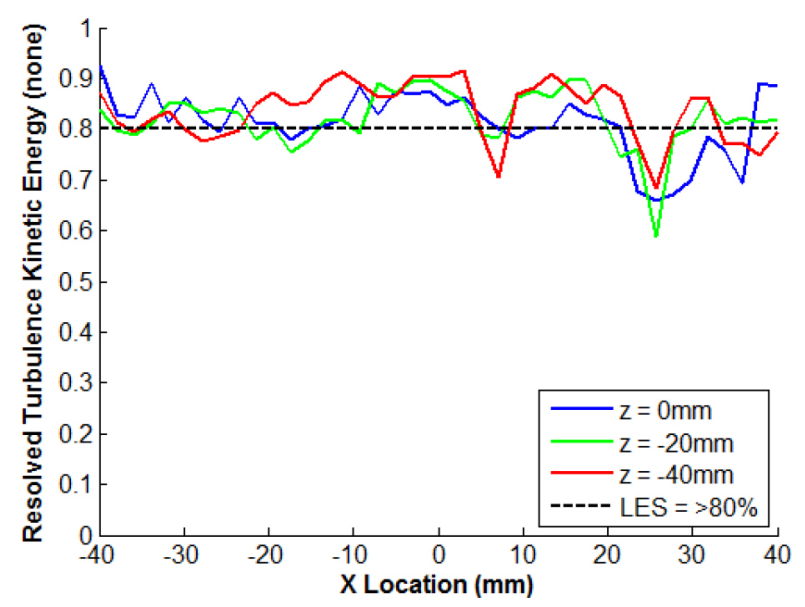

Figure 2. Resolution of Turbulence Kinetic Energy as a function of X-axis Position at $510^{\circ}$ c.a.

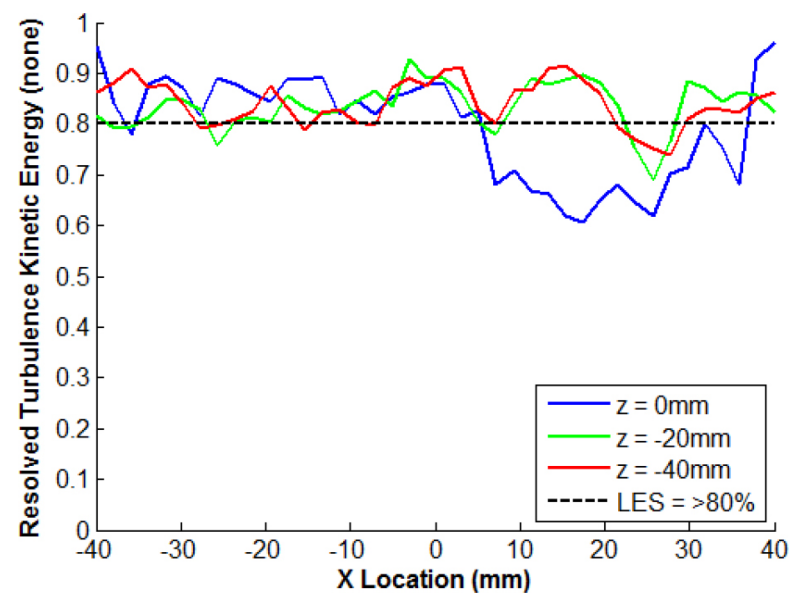

Figure 3. Resolution of Turbulence Kinetic Energy as a function of X-axis Position at $540^{\circ} \mathrm{c}$.a.

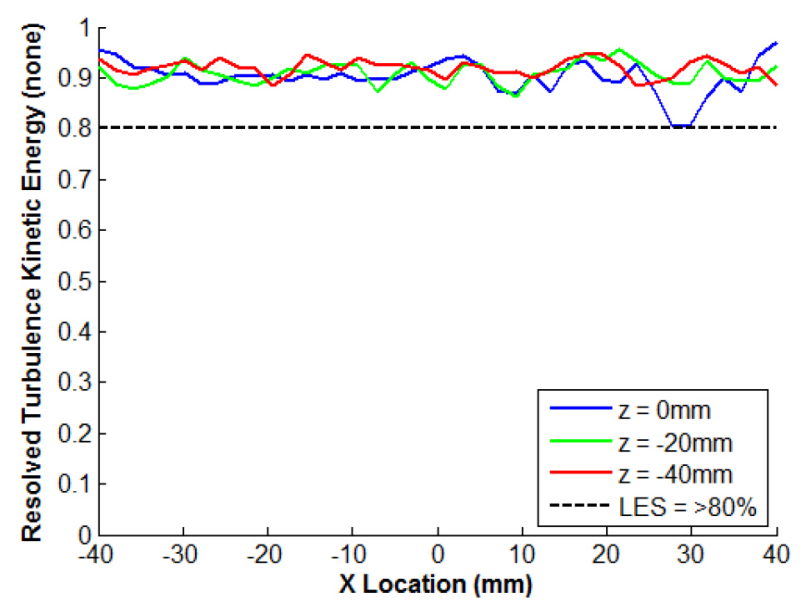

Figure 4. Resolution of Turbulence Kinetic Energy as a function of X-axis Position at $630^{\circ}$ c.a.

As a caveat, it is known that the resolution of turbulence kinetic energy is dependent on both the filter width and the SGS model used. The Smagorinsky SGS model used in this study is a turbulent viscosity based approach and is well known for being overly dissipative of kinetic energy, especially when used with a coarse mesh [18]. Hence results for turbulence resolution should be used with care since due to its dissipative nature and viscosity closure approach, the turbulence model can suggest that a greater amount of kinetic energy is being resolved than is reality.

\section{Model Validation}

The mean velocity $(\hat{u})$ and root mean square of the fluctuating velocity $\left(u_{r m s}^{\prime}\right)$ are compared against 100 cycle ensemble averaged experimental data extracted from [19]. Velocity magnitudes for all 29 individual LES cycles are also shown in the background of the figures to illustrate the level of CCV present. Predictions using a RNG k- $\varepsilon$ turbulence model are also shown for completeness and validation of the RANS predictions against experimental data is already documented in [12]. Note that it was not possible to extract experimental data for fluctuating velocity at $440^{\circ} \mathrm{c}$.a. hence only CFD results are shown.

As can be seen from Figure 5, Figure 6 and Figure 7, in some cases, particularly earlier in the intake stroke, the LES predictions fail to accurately capture the positioning and magnitude of some of the large scale eddies present within the cylinder. Of the crank angles and positions considered, perhaps $440^{\circ} \mathrm{c}$.a. at $\mathrm{z}=-8 \mathrm{~mm}$, as shown in Figure 5, could be considered the position with the largest source of difference between experimental and predicted results. To illustrate where this difference originates, Figure 8 shows the experimental and LES predicted flow field at $440^{\circ} \mathrm{c}$.a., with the $\mathrm{z}=-8 \mathrm{~mm}$ cutting plane highlighted by a bold dashed red line. It can be seen that in the experimental results this cutting plane intersects a recirculation region high in the cylinder at $10 \mathrm{~mm}<\mathrm{x}<30 \mathrm{~mm}$, whereas it can be seen that in the LES results this same recirculation region is predicted lower in the cylinder and hence a difference is seen in the mean 
velocity profile as shown in Figure 5. Despite these observed differences, it is seen that generally the LES model well predicts both the mean and fluctuating velocity components and in most cases provides better agreement than RANS.
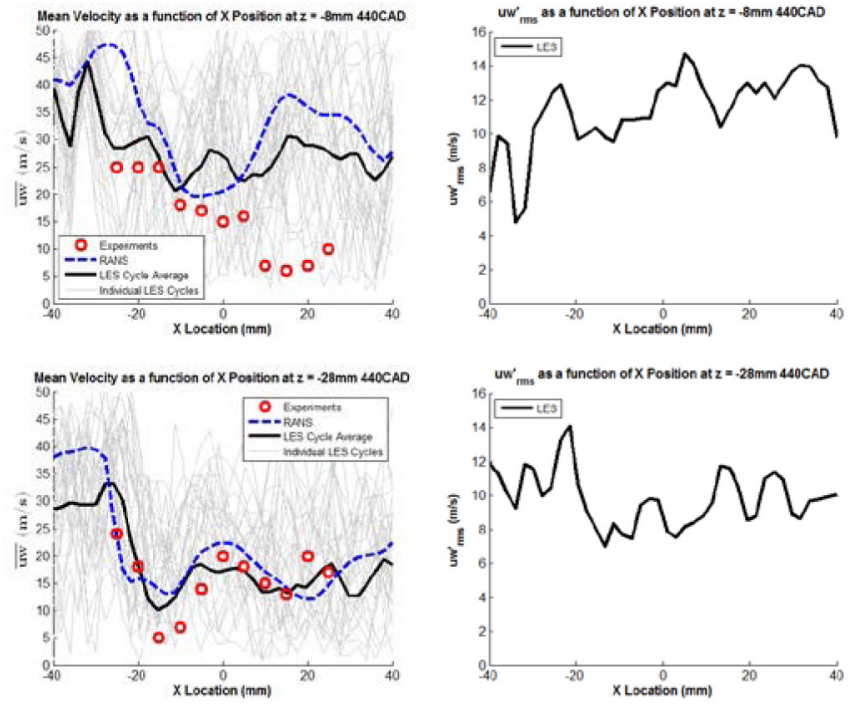

Figure 5. Mean and RMS Fluctuating Velocity at $440^{\circ} \mathrm{c}$.a.
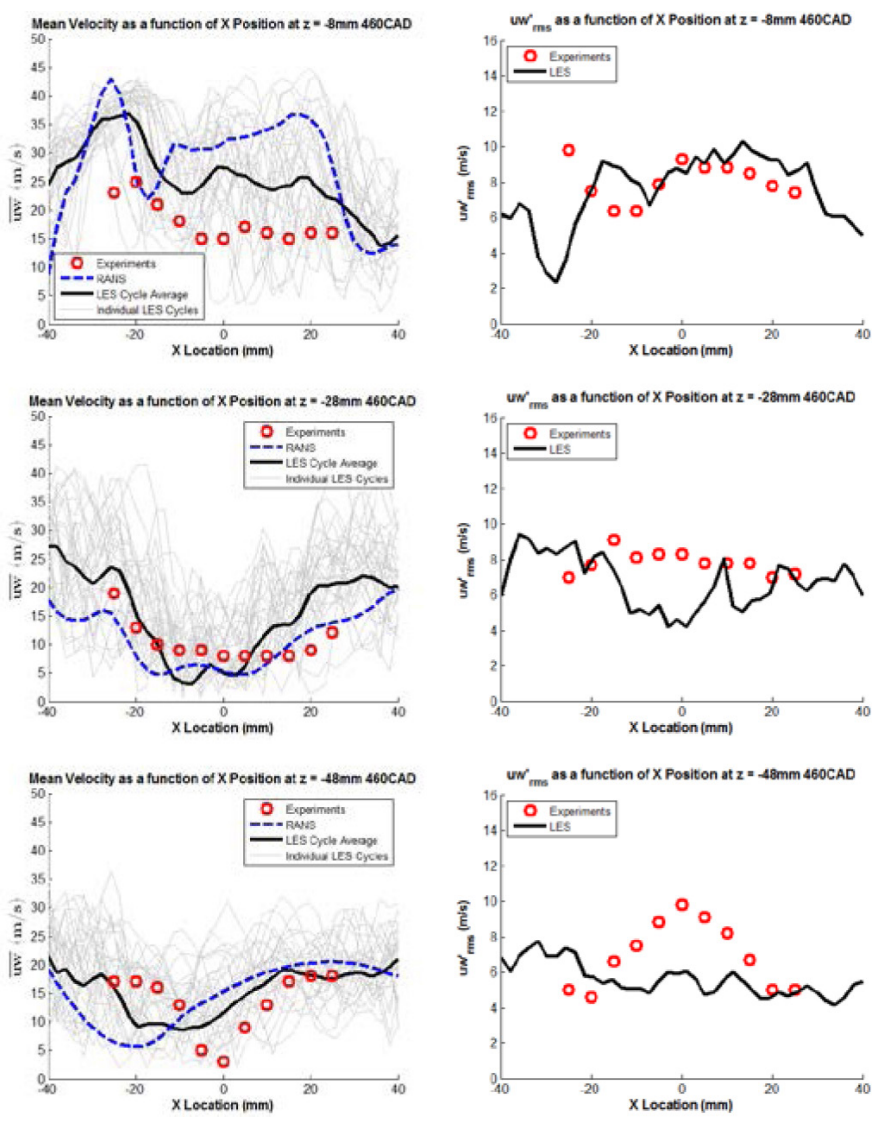

Figure 6. Mean and RMS Fluctuating Velocity at $460^{\circ}$ c.a.
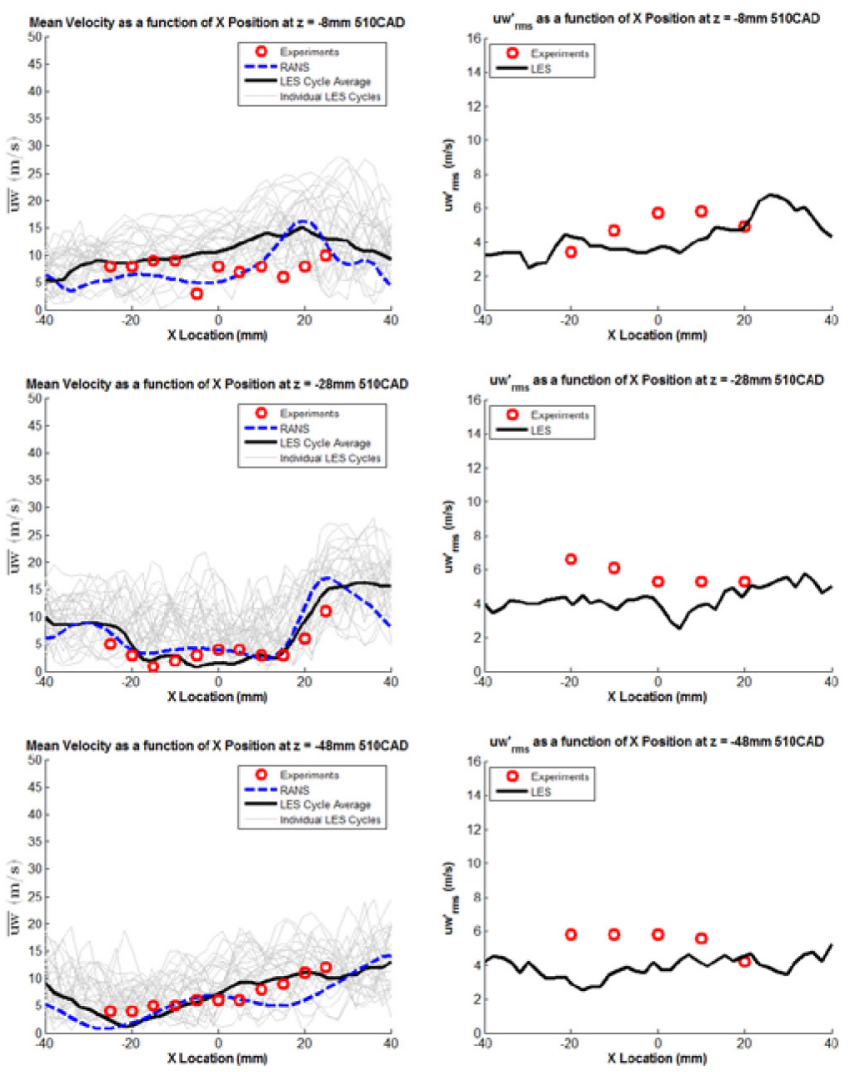

Figure 7. Mean and RMS Fluctuating Velocity at $510^{\circ} \mathrm{c} . \mathrm{a}$.

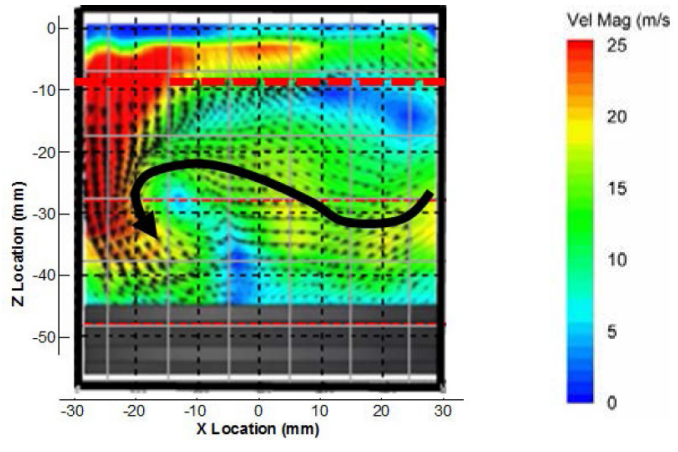

a.

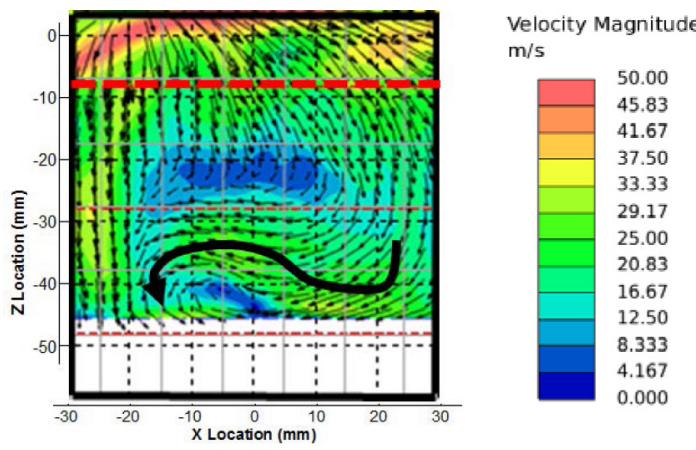

b.

Figure 8. (a) Experimental mean low frequency flow field captured with HSDPIV at a rate of $1.5 \mathrm{kHz}$ [19], (b) LES 29 cycle ensemble-average velocity contours and vectors, along the bore centreline at $440^{\circ} \mathrm{c}$.a. Dashed red line at $\mathrm{Z}=-8 \mathrm{~mm}$ used to highlight difference in flow field between Experimental and LES velocity predictions 


\section{POD Analysis}

As discussed above, the POD 'method of snapshots' approach was applied across 29 LES cycles through the intake and compression stroke up to and including spark timing. Initially the number of modes required to capture $90 \%$ of the total kinetic energy is plotted for each velocity component at specific crank angles and shown in Figure 9.

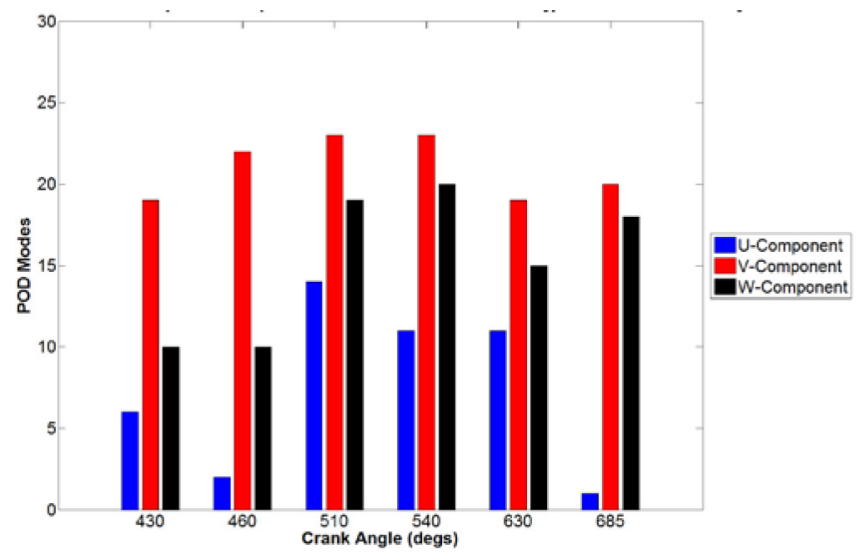

Figure 9. Number of Modes Required to Capture 90\% of the Flow Kinetic Energy for each Velocity Component at Discrete Crank Angles

From Figure 9 it is clear that a significantly lower number of modes are required to capture the majority of the kinetic energy in the $\mathrm{x}$-axis (U-velocity component); the intake port geometry and valve positioning generate a strong cross-cylinder flow field. Conversely, relatively weak flow structures are generated in the y-axis (V-velocity component) and consequently require a larger number of modes to capture the bulk of the kinetic energy. Early in the intake stroke a tumble charge motion is generated in the z-axis (W-velocity component) but this large scale flow motion is compressed and dissipated into smaller eddy length scales and less dominant flow structures during the compression stroke. Correspondingly, a lower number of modes are required to capture the majority of the kinetic energy for the W-velocity component during the intake stroke but increasing through the compression stroke up to spark timing.

In Figure 10, the energy captured against POD mode is shown in more detail. When examining the eigenvalue data in this manner, it is possible to deduce additional information about the structure of the in-cylinder flow field. When eigenvalue/energy data is examined in this format it is pertinent to evaluate the shape of the decay of eigenvalue/energy by POD mode; a steep gradient indicating that the majority of the energy is contained in the first mode and a strong or highly organised flow field is present, whereas a gradual gradient indicates that the flow energy is spread across a number of modes and hence a weak or disorganised flow field is present. Based on this, it is possible to evaluate the previous conclusions with regard to strength of the flow field in each plane.

Based on Figure 9, it was suggested that the V-velocity component (y-axis) exhibited a weak and disorganised flow field throughout the intake and compression stroke due to the large number of modes required to capture the majority of the flow kinetic energy but upon inspection of Figure 10 it is clear that the flow field is perhaps more organised than originally suggested. Examining the V-component at $430^{\circ} \mathrm{C}$.a. shows that whilst it does require a large number of modes to capture the majority of the flow energy, early in the intake stroke it still has a significant quantity of energy contained in the first mode, and only requires several more mode to capture $90 \%$ of the energy due to the following modes containing very little of the flow energy. Comparing the energy profile at $430^{\circ} \mathrm{c}$.a. with that at $685^{\circ} \mathrm{c}$.a. (spark timing), a very different energy profile can be seen. Significantly less energy is present in the first mode, with a greater quantity spread across the first seven modes. This observation suggests that the choice of fraction to define the majority of flow kinetic energy $(90 \%$ in this study) can influence the conclusions drawn about the strength of the flow field and that additional information gleaned from review of the eigenvalue/energy data by mode is also useful for evaluating the in-cylinder flow field.
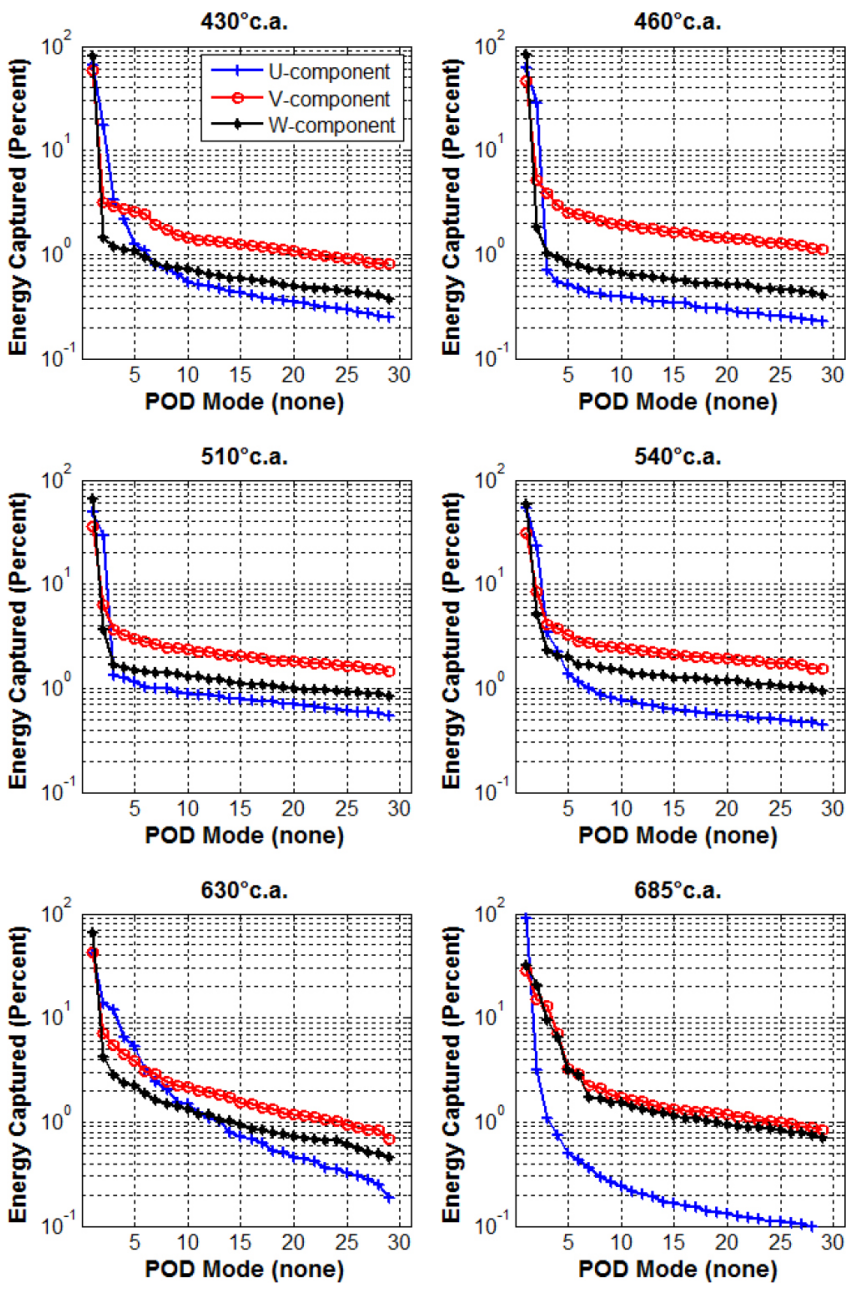

Figure 10. Comparison of Energy Captured as a Function of POD Mode for Each Velocity Component at Discrete Crank Angles

It is clear that the eigenvalue/energy data that is available from a POD analysis can be used to provide quantitative information about the characteristics of in-cylinder flow field throughout the engine cycle and it is expected that this could be a useful method for quantitatively comparing an engine design:

- The expected level of charge mixing through large scale charge motion, i.e. high tumble levels could be deduced via a small number of modes to capture the majority of the flow energy and a steep drop in energy captured against POD for $\mathrm{x}$ - and $\mathrm{z}$-axis velocity components

- The level of small scale turbulence present at the point of spark timing, i.e. high turbulence levels deduced via a large number 
of modes is required to capture the majority of the flow energy and gradual drop in energy capture against POD in all velocity components.

If it is assumed that at the limit where there is no CCV present in the original velocity field, the standard deviation of the time varying coefficients $\left(a^{(k)}(t)\right)$ for each POD mode would tend to zero. Hence the cycle-by-cycle variation of the time varying coefficients can be used to directly assess the $\mathrm{CCV}$ present within the in-cylinder flow structures.

First, the time coefficient results for velocity in the x-axis (U-velocity component) are examined, Figure 11 (a) and (b). Early in the cycle the time coefficient for Mode 1 appears to have relatively high magnitude variation and with low standard deviation, but later in the compression stroke (around $600^{\circ} \mathrm{c}$.a.) the time coefficients exhibits a significant rise in standard deviation. Mode 2 on the other hand shows significant magnitude and standard deviation most of the way through the intake stroke, rising quickly after $\operatorname{TDC}\left(360^{\circ} \mathrm{c}\right.$.a. $)$ but damping out by BDC $\left(540^{\circ}\right.$ c.a.) and then showing a small rise again through the mid portion of the compression stroke. Modes 3 and 4 show very similar characteristics where moderate levels of dispersion both early in the intake stroke and mid compression stroke are observed.

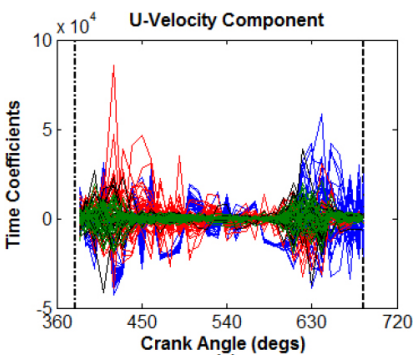

a.

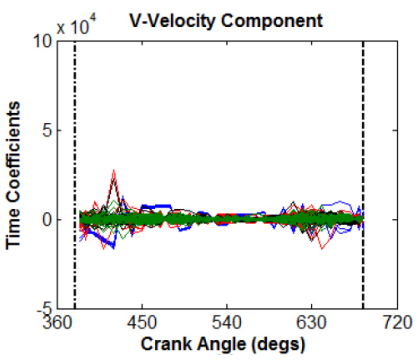

c.

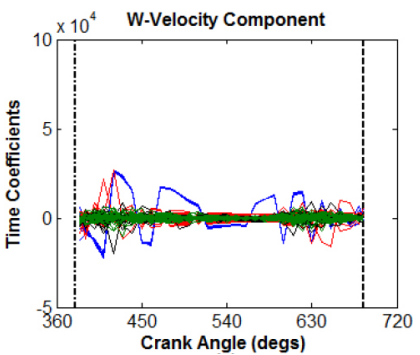

e.

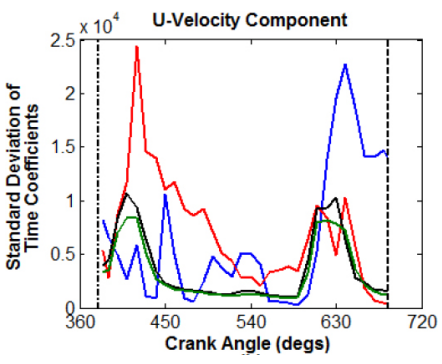

b.

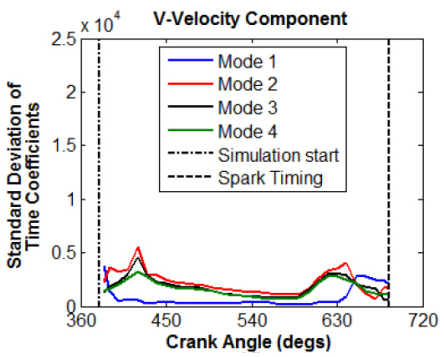

d.

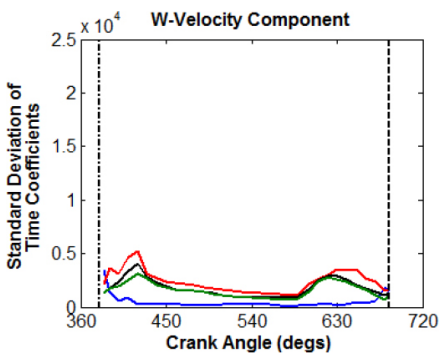

f.
Figure 11. Time varying Coefficients for each Velocity Component: (a) (c) (e) showing the time varying coefficients, (b) (d) (f) showing the standard deviation of the time varying coefficients
When the intake valve lift profile is overlaid (shown in Figure 12), it is clear that that the intake valve opening and closing event is a significant driver for CCV. During the early opening period when the intake valve effective area is small, orifice discharge coefficient low and expansion ratio across the valve high, flow velocities rise quickly as the valve jet forms and begins to stabilise. As can be seen from the POD analysis, this generates significant $\mathrm{CCV}$, particularly within the smaller and less dominant flow structures. This is evident from the dispersion within modes 2-4 being more significant than mode 1 . During the intake valve closing period, high levels of CCV in the small scale structures becomes present again but a high level of dispersion, and hence $\mathrm{CCV}$, is also seen in the larger scale flow structures (mode 1).

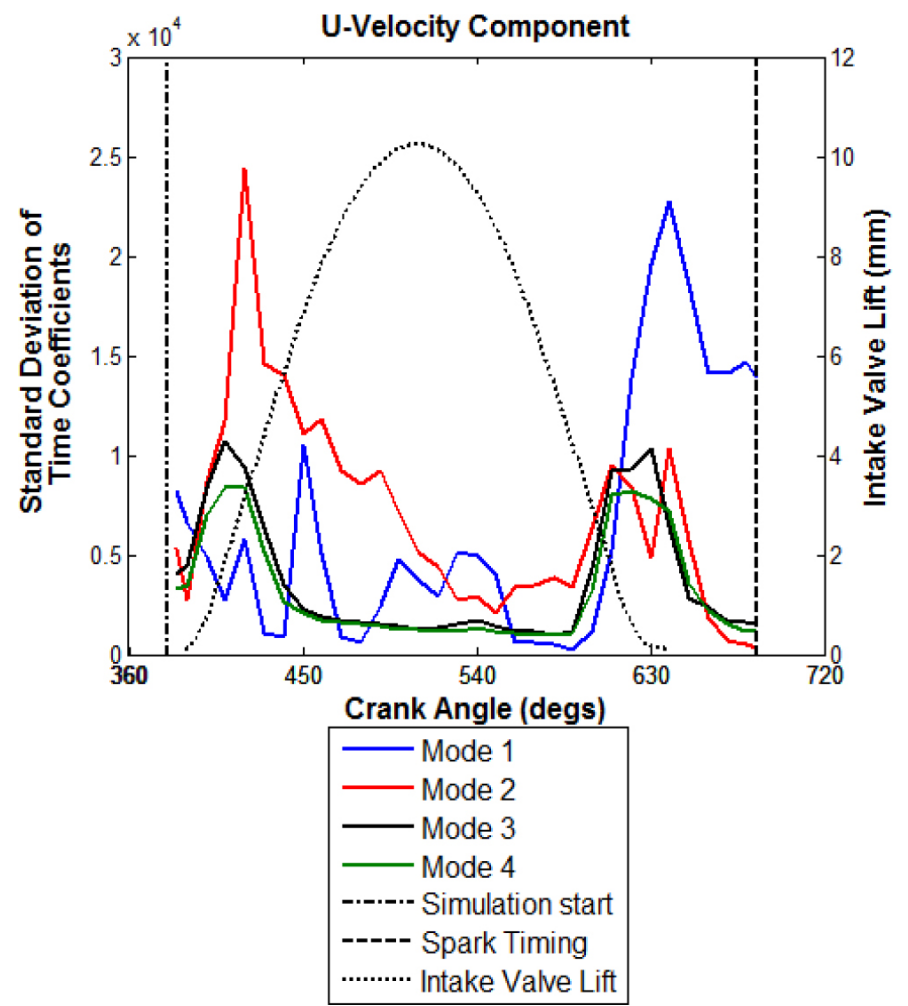

Figure 12. Standard Deviation of the Time Varying Coefficients for U-velocity component with intake valve lift profile overlaid

The coefficient dispersion in the V- (Figure $11 \mathrm{c}-\mathrm{d}$ ) and W-velocity components (Figure $11 \mathrm{e}-\mathrm{f}$ ) is seen to be of significantly smaller magnitude and in particular, coefficient dispersion of Mode 1 is seen to be lower than all other modes. Examining the energy content of each mode for $\mathrm{V}$ - and $\mathrm{W}$-velocity components against crank angle (Figure $13 \mathrm{~b}-\mathrm{c}$ ), shows that mode 1 contains a significantly greater fraction of the energy content in the $\mathrm{V}$ - and $\mathrm{W}$-velocity components than is seen in the U-velocity component (Figure 13 a). This agrees with previous discussions; higher modes are related to larger scale flow structures that will exhibit lower levels of $\mathrm{CCV}$, hence a greater fraction of energy being present in mode 1 will contribute to overall lower levels of CCV. 

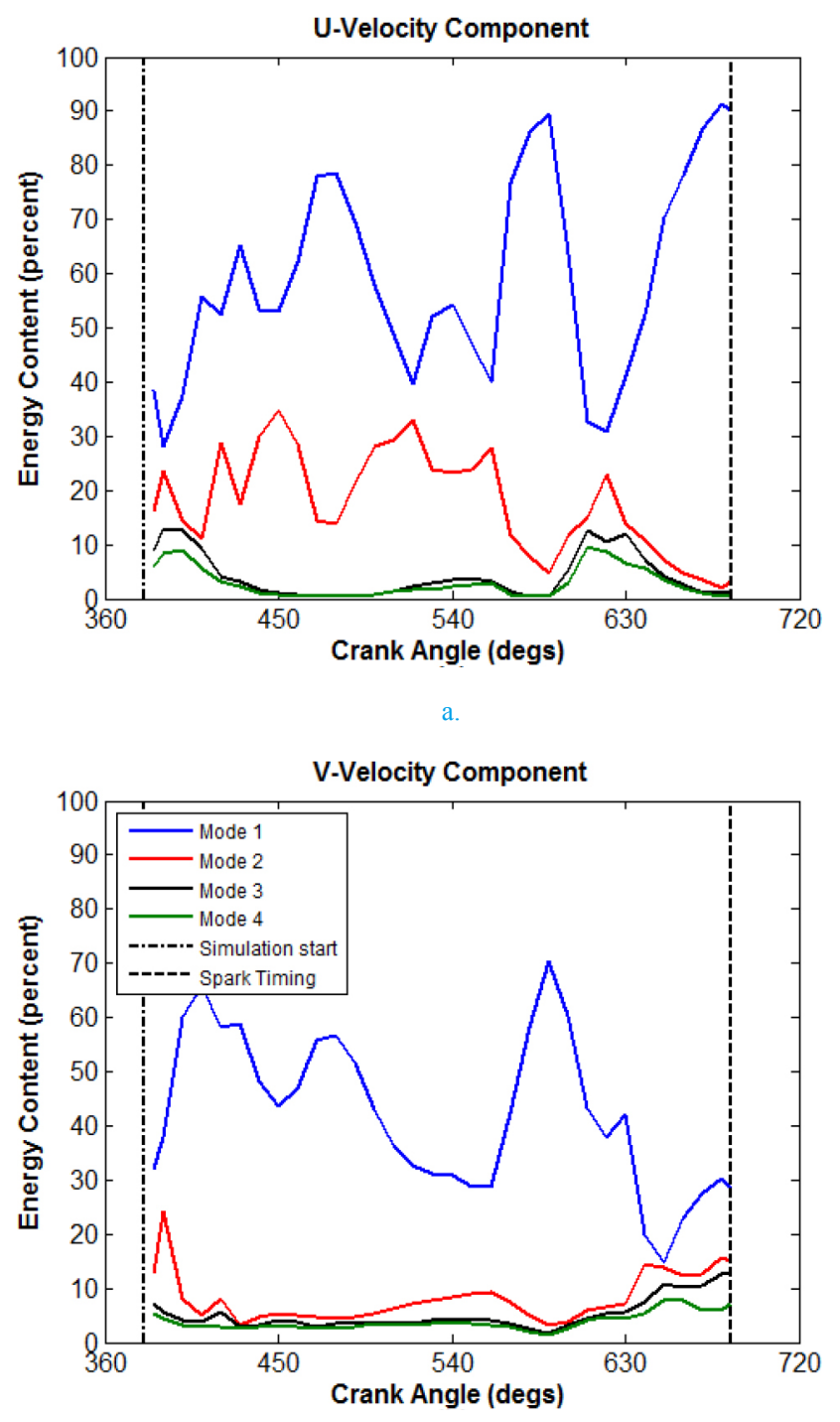

b.

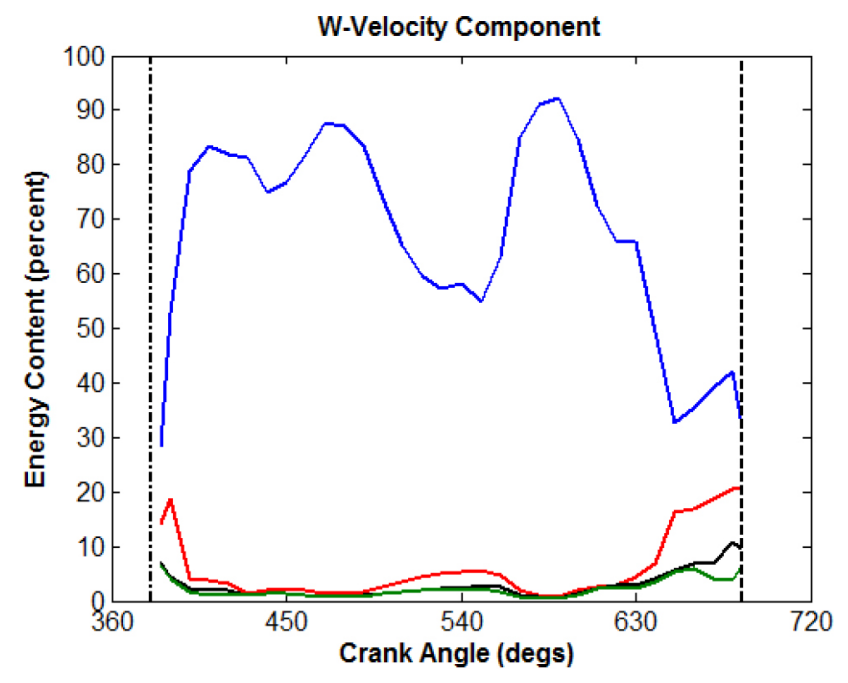

Figure 13. Energy Content as a function of Crank Angle for each Velocity Component
Using the time varying coefficients directly to assess the total level of $\mathrm{CCV}$ present must be done cautiously since the level of $\mathrm{CCV}$ present in each mode is a function of both the magnitude of time varying coefficient and the total fraction of energy present in that particular mode.

Fontanesi [ $\underline{5}$ ] proposed the use of the of a 'CCV RMS Index' as a method of examining the variation in $\mathrm{CCV}$ through an engine cycle by summing the root mean square of the energy weighted time varying coefficients. This approach has been applied to the data presented here and the method used for calculating individual modes ' $C C V_{\text {index_rms, } M}$ ' and the overall ' $C C V_{\text {index_rms, Overall }}$ is shown in equations (9) and (10), the results of which are shown for each velocity component in Figure 14.

$$
\begin{gathered}
C C V_{\text {index }}=\sqrt{\frac{1}{k} \sum_{k=1}^{M}\left(a^{(k)}(t)-\left\langle a^{(k)}(t)\right\rangle\right)^{2}} \\
\cdot \frac{\lambda^{(k)}}{\sum_{k=1}^{M} \lambda^{(k)}}
\end{gathered}
$$

$$
\begin{aligned}
C C V_{\text {index }} \text { rms,overall } & =\sum_{k=1}^{M}\left[\sqrt{\frac{1}{k} \sum_{k=1}^{M}\left(a^{(k)}(t)-\left\langle a^{(k)}(t)\right\rangle\right)^{2}}\right. \\
& \left.\cdot \frac{\lambda^{(k)}}{\sum_{k=1}^{M} \lambda^{(k)}}\right]
\end{aligned}
$$

The results again indicate that a greater level of CCV is present in the $\mathrm{U}$-velocity component (x-axis) and, similarly to previous findings and expectation:

- $\quad \mathrm{CCV}$ is highest around TDC when length scales are most wall bounded and during the intake valve opening and closing event when large changes in effective flow area generate valve jet $\mathrm{CCV}$

- $\quad \mathrm{CCV}$ is lowest around BDC when flow structures are least wall bounded and large scale structure less susceptible to $\mathrm{CCV}$ are able to form

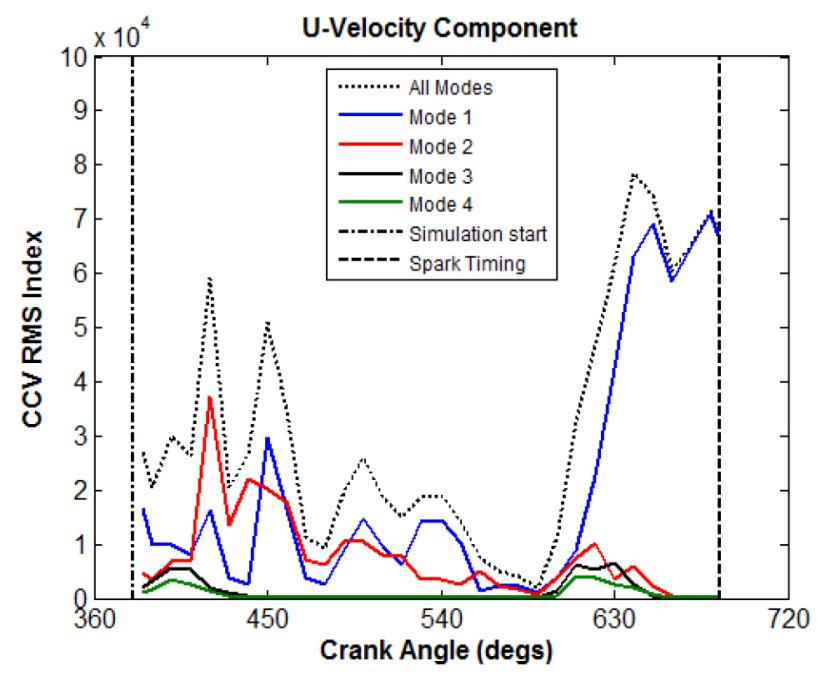

a.

Figure 14. CCV RMS Index as a function of Crank Angle for each Velocity Component. Note: different y-axis scales used to improve figure clarity 


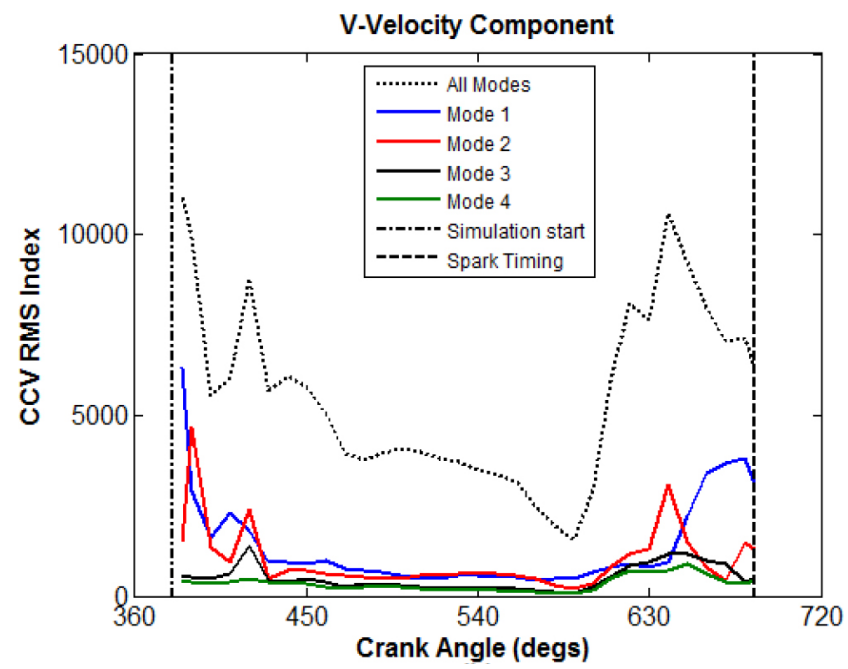

b.

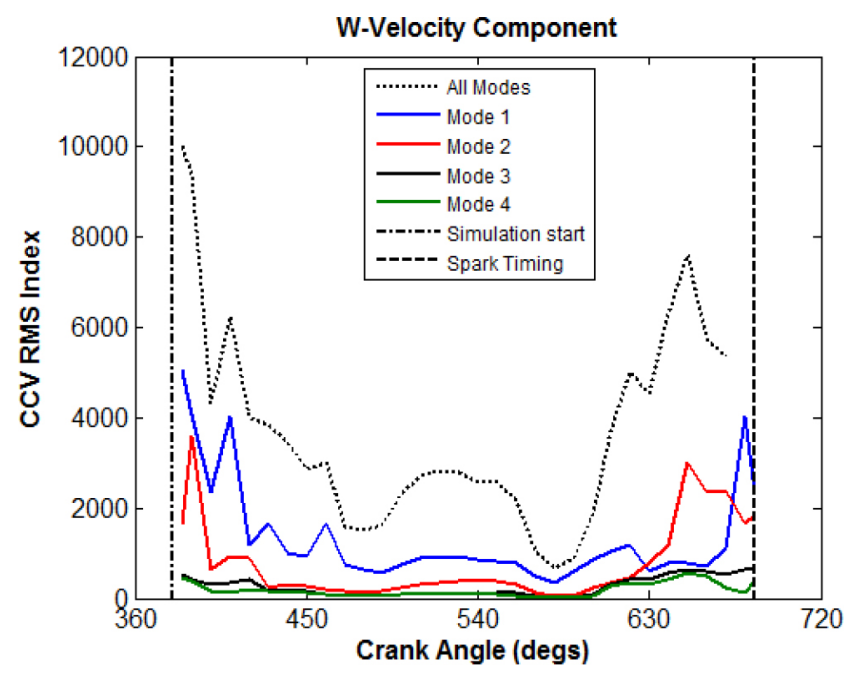

c.

Figure 14. (cont.) CCV RMS Index as a function of Crank Angle for each Velocity Component. Note: different y-axis scales used to improve figure clarity

In [4] it was proposed that the eigenvalue/energy data could be used as a means to deduce the level of statistical convergence of the ensemble-average solution by comparing the eigenvalue/energy content by mode for a varying number of snapshots. Once the curves for a certain number of snapshots overlaid, it could be deduced that there were sufficient snapshots/cycles to provide a statistically representative ensemble average of the in-cylinder flow field. This approach has been applied in this study at:

- $460^{\circ}$ c.a. - intake stroke, many large scale turbulent structures, less $\mathrm{CCV}$ present

- $685^{\circ}$ c.a. - spark timing, predominantly small scale structures, high CCV present

As seen in Figure 15, the results indicate that the dominant flow structures present in the $\mathrm{x}$-axis (U-Velocity Component) require a smaller number of cycles to achieve statistical convergence, with 25 and 29 snapshots having effectively converged at both crank angles examined here. Due to the weaker and smaller length scale structures present in the $\mathrm{y}$ - and $\mathrm{z}$-axes, greater dispersion is present between the series and none appear to converge for the number of snapshots presented here. This is not surprising since the engine in question was known to exhibit high levels of CCV and the experimental procedure typically included capturing 100-120 engine cycles to ensure statistical convergence and to capture the full range of the CCV.
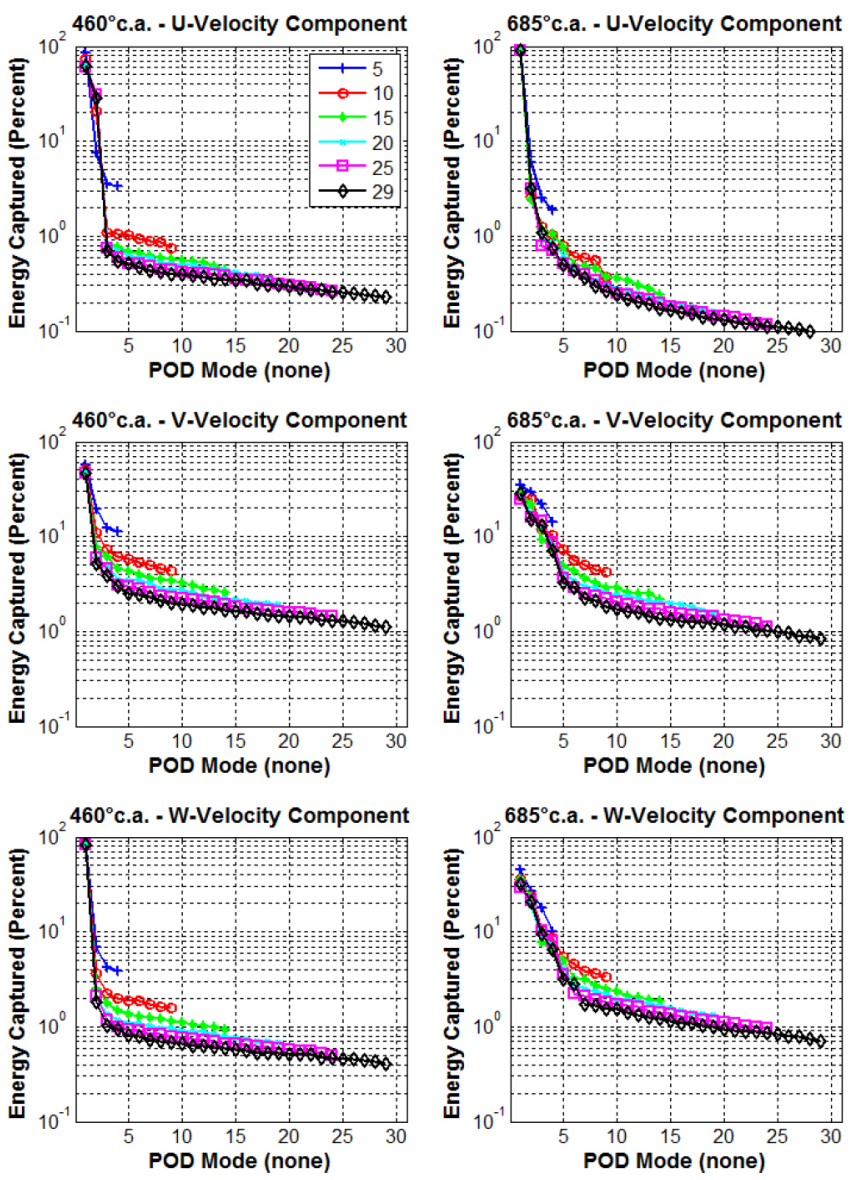

Figure 15. Comparison of Energy Captured as a Function of POD Mode with a Varying Number of Snapshots for each Velocity Component at $460^{\circ} \mathrm{c}$.a. and $685^{\circ}$ c.a.

\section{Conclusions}

A numerical study of a gasoline direct injection engine flow using the Large Eddy Simulation (LES) modelling technique has been carried out over 30 successive engine cycles. The following findings may be drawn:

- A turbulence resolution parameter was used to evaluate the mesh suitability at three different crank angles along three swirl cutting planes. The results showed the mesh to generally allow greater than $80 \%$ of the flow turbulence kinetic energy to be resolved and less than $20 \%$ modelled within the sub-grid scale.

- The calculated mean and root mean square of the fluctuating velocity components have been validated against experimental data and showed that generally the velocity profiles are well predicted. However, some disagreement on the positioning and magnitude of some of the large scale eddies early in the intake stroke are observed.

- The Proper Orthogonal Decomposition methodology was applied to the velocity field data with a view to using the approach to evaluate the turbulent structures and cyclic variability within the flow field. 
- Inspection of the number of modes to capture $90 \%$ of the flow turbulence kinetic energy pointed to a dominant cross-cylinder flow field and weak flow field front-to-rear during the intake valve open period, as would be expected by the port and valve positioning. The result also suggested a relatively dominant flow structure in the z-axis due to the tumble motion generated by the intake ports. Further review of the energy content by mode revealed additional details about the strength of the flow field and size of flow structures that is lost when only evaluating the number of modes to capture the majority of flow energy.

- It was observed that at the limit of zero $\mathrm{CCV}$, the variation in time varying coefficients would also tend to zero, hence could be used as a means of quantifying the level of CCV present at different points through the cycle. Analysis of the time varying coefficients indicated that the intake valve opening and closing event was a significant precursor to $\mathrm{CCV}$, with lowest levels of $\mathrm{CCV}$ present around BDC where the geometry allows large scale flow structures to form that are less easily influenced by $\mathrm{CCV}$.

- Finally, the number of snapshots was varied as a means of evaluating the level of statistical convergence of the ensemble average for the number of engine cycles completed. In this example, the results suggested that additional cycles are needed to fully capture the $\mathrm{CCV}$ present.

\section{References}

1. Ozdor, N., Dulger, M., and Sher, E., "Cyclic Variability in Spark Ignition Engines A Literature Survey," SAE Technical Paper 940987, 1994, doi:10.4271/940987.

2. Davis, G. and Borgnakke, C., "The Effect of In-Cylinder Flow Processes (Swirl, Squish and Turbulence Intensity) on Engine Efficiency - Model Predictions," SAE Technical Paper $\underline{820045}$, 1982, doi: $10.4271 / 820045$.

3. Lebrère, L. and Dillies, B., "Engine Flow Calculations Using a Reynolds Stress Model in the Kiva-II Code," SAE Technical Paper 960636, 1996, doi:10.4271/960636.

4. Liu, K. and Haworth, D., "Development and Assessment of POD for Analysis of Turbulent Flow in Piston Engines," SAE Technical Paper 2011-01-0830, 2011, doi:10.4271/2011-01$\underline{0830 .}$.

5. Fontanesi, S., Paltrinieri, S., and Cantore, G., "LES Analysis of Cyclic Variability in a GDI Engine," SAE Technical Paper 201401-1148, 2014, doi:10.4271/2014-01-1148.

6. Smagorinsky, J., "General circulation experiments with the primitive equations. I. The basic experiment," Mon. Weather Rev. 91(3):99-164, 1963.

7. Lumley, J.L., "The Structure of Inhomogeneous Turbulent Flows," Atmospheric Turbulence and Radio Wave, Nauka, Moscow, 1967, 166-178, 1967.

8. Sirovich, L., "Turbulence and the Dynamics of Coherent Structures,” Q. Appl. Math. 45:561-590, 1987.

9. Fogleman, M., Lumley, J., Rempfer, D., and Haworth, D., "Application of the proper orthogonal decomposition to datasets of internal combustion engine flows," J. Turbul. 5(September 2015), 2004, doi:10.1088/1468-5248/5/1/023.
10. Justham, T., Jarvis, S., Garner, C., Hargrave, G. et al., "Single Cylinder Motored SI IC Engine Intake Runner Flow Measurement Using Time Resolved Digital Particle Image Velocimetry," SAE Technical Paper 2006-01-1043, 2006, doi:10.4271/2006-01-1043.

11. Jarvis, S., Justham, T., Clarke, A., Garner, C. et al., "Motored SI IC Engine In-Cylinder Flow Field Measurement Using Time Resolved Digital PIV for Characterisation of Cyclic Variation," SAE Technical Paper 2006-01-1044, 2006, doi:10.4271/200601-1044.

12. Beavis, N.J., Ibrahim, S.S., Manickam, P.K., and Malalasekera, W., "Characteristics of GDI Engine Flow Structures," 12th International Congress, Engine Combustion Processes, Current Problems and Modern Technologies, March 12th-13th, 2015, Ludwigsburg, Germany, 1-12, 2015.

13. Issa, R.I., "Solution of the implicitly discretised fluid flow equations by operator-splitting," J. Comp. Phys. 62:40-65, 1986.

14. Issa, R.I., Gosman, A.D., and Watkins, A.P., "The computation of compressible and incompressible recirculating flows by a non-iterative implicit scheme," J. Comp. Phys. 62:66-82, 1986.

15. Dugué, V., Gauchet, N., and Veynante, D., "Applicability of Large Eddy Simulation to the Fluid Mechanics in a Real Engine Configuration by Means of an Industrial Code," SAE Technical Paper 2006-01-1194, 2006, doi:10.4271/2006-01-1194.

16. Pope, S.B., "Turbulent Flows," First edit, Cambridge University Press, ISBN 978-0-521-59886-6, 2000.

17. Pope, S.B., "Ten questions concerning the large-eddy simulation of turbulent flows," New J. Phys. 6, 2004, doi:10.1088/13672630/6/1/035.

18. Rutland, C.J., "Large-eddy simulations for internal combustion engines - a review," Int. J. Engine Res. 12(5):421-451, 2011, doi:10.1177/1468087411407248.

19. Justham, T., "Cyclic Variation in the Flow Field Behaviour within a Direct Injection Spark Ignition Engine: A High Speed Digital Particle Image Velocimetry Study," Loughborough University, PhD. Thesis, 2010.

\section{Contact Information}

Nick Beavis

Department of Aeronautical and Automotive Engineering

Loughborough University

Loughborough

UK

LE11 3TU

N.Beavis@lboro.ac.uk

\section{Acknowledgments}

This work was supported by Jaguar Land Rover and the UK-EPSRC grant EP/K014102/1 as part of the jointly funded Programme for Simulation Innovation. The authors would also like to thank JLR for supplying of the original CAD model and continued technical support. 


\section{Nomenclature}

$\mathbf{a}^{(\mathbf{k})}(\mathbf{t})$ - POD Time varying coefficients

$\boldsymbol{k}_{r e s}(\boldsymbol{x}, \boldsymbol{t})$ - Resolved turbulence kinetic energy

$\boldsymbol{k}_{s g s}(\boldsymbol{x}, \boldsymbol{t})$ - SGS turbulence kinetic energy

$\mathbf{u}(\mathbf{x}, \mathbf{t})$ - Time dependent velocity field

$\boldsymbol{u}_{\boldsymbol{i}}$ - Instantaneous velocity

$\hat{u}_{i}$ - Mean velocity

$u_{i}^{\prime}$ - Fluctuating velocity

$\mathbf{u}^{\prime}{ }_{\text {rms }}$ - RMS of fluctuating velocity

$\mathbf{A}^{(\mathrm{k})}$ - POD Eigenvectors

$C_{S}$ - Smagorinsky constant
$\mathbf{C C V}_{\text {index_rms, } \mathbf{M}}-$ Modal CCV RMS Index

$\mathbf{C C V}_{\text {index_rms,Overall }}$ - Total CCV RMS Index

M - POD Spatial basis functions

$M_{r e s}(x, t)$ - Turbulence resolution parameter

$\bar{S}$ - Favre averaged strain rate tensor

$V$ - Cell volume

$\lambda^{(\mathrm{k})}$ - POD Eigenvalue

$v_{T}$ - Turbulence viscosity

$\psi^{(\mathbf{k})}(\mathbf{x})$ - POD mode

$\Delta$ - Filter width

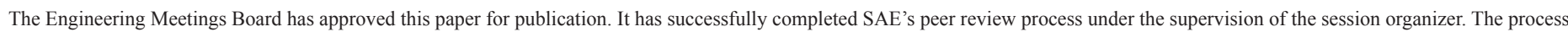
requires a minimum of three (3) reviews by industry experts.

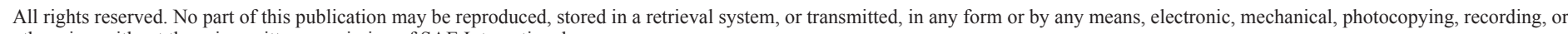
otherwise, without the prior written permission of SAE International.

Positions and opinions advanced in this paper are those of the author(s) and not necessarily those of SAE International. The author is solely responsible for the content of the paper.

ISSN 0148-7191

$\underline{\text { http://papers.sae.org/2016-01-0598 }}$ 